\title{
UMA EXPERIÊNCIA NO ENSINO DE CLIMATOLOGIA ESCOLAR
}

\author{
ALLOCCA, Rodson de Andrade - rodson.ufv@gmail.com \\ Universidade Federal do Espírito Santo/ UFES
}

FIALHO, Edson Soares- fialho@ufv.br Universidade Federal de Viçosa/ UFV

Submetido em: 04/09/2020

\begin{abstract}
RESUMO: No Ensino Médio, o conteúdo de climatologia, que é denso e complexo, muitas vezes, não é apresentado de forma articulada com a rotina cotidiana e vivências dos discentes, acarretando um distanciamento e um desinteresse sobre a temática, transformando a imagem do conteúdo em algo inacessível e difícil. Nesse sentido, a utilização de novas práticas educativas se faz necessária para viabilizar e potencializar o interesse dos discentes no âmbito da ciência geográfica. Para isso, utilizou-se a prática do trabalho de campo como uma opção metodológica e nessa proposta os conhecimentos dos alunos sobre a localização da escola e seu entorno imediato puderam ser relacionados com o comportamento do campo térmico local e seus possíveis condicionantes. Essa experiência permitiu aos discentes ter contato com o "fazer científico" e, sob esse prisma, um novo olhar sobre a aplicabilidade dos conhecimentos geográficos. Após a apresentação dos conteúdos sobre climatologia em sala de aula, os discentes tiveram que planejar, projetar, coletar e analisar os dados que serviram de base para a espacialização das informações produzidas. Os resultados obtidos por meio dos registros térmicos puderam ser comparados aos resultados das entrevistas aplicadas junto aos alunos sobre a percepção do campo térmico local. Apesar de discordantes quando comparados, os resultados obtidos serviram como base para a discussão sobre espacialização da temperatura do ar nos arredores do Instituto Montessori de Ponte Nova-MG.
\end{abstract}

PALAVRAS-CHAVE: Climatologia; Ensino; Escola.

\section{AN EXPERIENCE IN THE TEACHING OF SCHOOL CLIMATOLOGY}

ABSTRACT: In high school, the climatology content, which is dense and complex, is often not presented in an articulated way with the students' daily routine and experiences, causing a detachment and a lack of interest in the theme, transforming the image of the content into something inaccessible and difficult. In this sense, the use of new educational practices is necessary to enable and enhance the interest of students in the scope of geographic science. For this, the practice of fieldwork was used as a methodological option and in this proposition the students' knowledge about the location of the school and its immediate surroundings could be related to the behavior of the local thermal field and its possible conditions. This experience allowed students to have contact with scientific practice and, from this perspective, a new look at the applicability of geographic knowledge. After presenting the contents about climatology in the classroom, the students had to plan, design, collect and analyze the data that served as a basis for the spatialization of the information produced. The results obtained through the thermal records could be compared to the results of the interviews applied to the students about the perception of the local thermal field. Despite disagreement when compared, the results obtained served as a basis for the discussion on spatialization of air temperature in the vicinity of the Montessori Institute of Ponte Nova-MG.

KEYWORDS: Climatology; Teaching; School. 


\section{UNA EXPERIENCIA EN LA ENSEÑANZA DE CLIMATOLOGÍA ESCOLAR}

RESUMEN: En el bachillerato, el contenido de climatología, que es denso y complejo, muchas veces no se presenta de manera articulada con la rutina y las experiencias diarias de los estudiantes, provocando un desapego y desinterés por el tema, transformando la imagen del contenido en algo inaccesible y difícil. En este sentido, el uso de nuevas prácticas educativas es necesario para habilitar y potenciar el interés de los estudiantes en el ámbito de la ciencia geográfica. Para ello, se utilizó la práctica del trabajo de campo como opción metodológica y en esta propuesta el conocimiento de los estudiantes sobre la ubicación de la escuela y su entorno inmediato podría relacionarse con el comportamiento del campo termal local y sus posibles condiciones. Esta experiencia permitió a los estudiantes tener contacto con la práctica científica y, desde esta perspectiva, una nueva mirada a la aplicabilidad del conocimiento geográfico. Luego de presentar los contenidos sobre climatología en el aula, los estudiantes debían planificar, diseñar, recolectar y analizar los datos que sirvieron de base para la espacialización de la información producida. Los resultados obtenidos a través de los registros térmicos se pudieron comparar con los resultados de las entrevistas aplicadas a los estudiantes sobre la percepción del campo térmico local. A pesar del desacuerdo al comparar, los resultados obtenidos sirvieron de base para la discusión sobre la espacialización de la temperatura del aire en las cercanías del Instituto Montessori de Ponte Nova-MG.

PALABRAS CLAVE: Climatología; Docencia; Escuela..

\section{INTRODUÇÃO}

O cotidiano da docência é repleto de desafios. Nesse sentido, um professor, ao receber seu diploma de graduação, habilitando-se para iniciar sua prática como docente, descobre que a maioria dos profissionais é forjada na rotina das salas de aula. Cada professor torna-se uma espécie de produto em construção contínua, incorporando a cada aula lecionada novas habilidades e estratégias fundamentais para $o$ sucesso no processo de ensino $e$ aprendizagem.

Embora cada profissional tenha suas experiências individuais, são semelhantes as dificuldades encontradas por muitos, sejam elas de caráter material (falta de recursos adequados), sejam de caráter formativo, sejam pelas demandas da rotina escolar ou por qualquer outro fator.

Um ponto de grande importância nesse vasto universo da docência é a discussão que se estabelece em relação a forma como os temas e os conteúdos são abordados em sala de aula. Nas aulas de didática durante a graduação e nos diversos cursos de formação, recorrentemente é reforçada a importância de que os professores consigam estabelecer a ligação entre os conteúdos acadêmicos e os escolares, trata-se da transposição didática.

É preciso discutir os conceitos científicos em uma linguagem que seja acessível aos educandos. Nesse sentido, o fracasso desse processo pode desencadear problemas na aprendizagem dos alunos. Não são raras as vezes em que o papel e a postura do professor são o gatilho para esse insucesso.

Na ciência geográfica é fundamental que o aluno seja levado por um caminho que prime pela articulação entre o teórico e o vivido. Sendo assim, o interesse do aluno passa a ser despertado quando encontra os pontos de contato entre o que se vê em sala de aula e o que é vivenciado em sua rotina diária. É papel do professor promover essa articulação. 
Para Fialho (2014), o desinteresse pelas questões geográficas decorre da sensação de inutilidade por parte dos alunos. Portanto, o foco deve ser uma aprendizagem dotada de significado. Para tanto, segundo Steinke (2012), a utilização de imagens como recurso didático pode contribuir na promoção de uma aprendizagem mais significativa dos conceitos de tempo e clima.

Não podemos reduzir as causas do sucesso ou insucesso do processo de ensino e aprendizagem a um único ator. Embora exercendo um papel de grande relevância, não é o professor o único responsável. O ideal é encontrar caminhos, discutir e refletir sobre a prática para melhor alcançar o objetivo.

O trabalho aqui apresentado é um pequeno relato de experiência que vai de encontro ao objetivo acima exposto. Trata-se da busca de transpor as barreiras diárias no exercício da profissão docente e ao mesmo tempo oferece uma alternativa de tornar mais significativa a abordagem geográfica do clima.

No ano de 2019, foi desenvolvida juntamente com os alunos do primeiro ano do ensino médio da Sociedade Educacional Montessori, de Ponte Nova - MG, uma proposta de pesquisa sobre o campo térmico de uma porção específica da área urbana do município. Essa proposta visava ser um experimento científico (pois abarcava procedimentos sistematizados e embasados pela teoria) e ao mesmo tempo pedagógico (pois configurou um esforço didático para que os alunos pudessem melhor compreender o tema).

Segundo Steinke et al. (2014, p.133),

[...] para a compreensão de conteúdos relacionados à Climatologia é necessário que o professor lance mão de outras práticas, recursos visuais e muitas ilustrações, pois o nível de abstração exigido para a compreensão dos fenômenos é elevado. Além disso, o professor também pode mostrar aos alunos que a Climatologia está presente no seu dia-a-dia.

Para Costa e Wollmann (2017, p. 190) "o ensino de Geografia carece de novas metodologias e recursos didáticos que propiciem aos educandos maior participação na construção do conhecimento". A proposta desenvolvida nessa experiência vai exatamente de encontro ao problema apontado pelos autores e tem como objetivo abordar os conteúdos climatológicos de forma prática e significativa, fazendo com que os resultados obtidos no processo de ensino e aprendizagem sejam satisfatórios em seu duplo propósito (científico e pedagógico).

\section{MATERIAL E MÉTODOS}

Para o desenvolvimento da proposta, considerando se tratar de uma ferramenta na abordagem do conteúdo previsto no programa de curso anual da componente curricular de Geografia no primeiro ano do ensino médio, inicialmente, foi apresentado em sala de aula a base teórica sobre a climatologia. Nesse momento, os alunos tiveram contato com os principais conceitos, dinâmicas e escalas climáticas.

O trabalho foi apresentado para os alunos tendo como base os resultados da experiência de pesquisa desenvolvida na área urbana de Ponte Nova por Allocca (2018), em sua dissertação apresentada junto ao Programa de Pós- 
Graduação em Geografia, da Universidade Federal do Espírito Santo, sendo requisito obrigatório para a obtenção do título de mestre.

$\mathrm{Na}$ pesquisa em questão foi feito um levantamento de dados de temperatura do ar coletados na área urbana da cidade de Ponte Nova, Minas Gerais, possibilitando o mapeamento do campo térmico da área pesquisada.

Na discussão da proposta juntamente com os alunos, ficou resolvido que o trabalho por eles desenvolvidos teria como objeto de pesquisa uma parte específica da área urbana do município e objetivava encontrar diferenças térmicas entre os pontos de coleta de dados. No desenvolvimento do trabalho os procedimentos adotados foram organizados em diferentes etapas, que serão apresentadas a seguir.

\section{APRESENTAÇÃo dA ÁREA DE PESQUISA}

Ponte Nova está localizado a aproximadamente duzentos quilômetros da capital do estado de Minas Gerais, Belo Horizonte. Segundo dados do IBGE (2010) o município possui uma população residente de 57.390 habitantes e conforme Allocca (2018) no âmbito microrregional é um importante centro de comércio e serviços. Ainda segundo Allocca (op. cit.), do ponto de vista geomorfológico, o relevo local é classificado como Domínio Morfoclimático dos Mares de Morros Florestados (AB'SABER, 2003), caracterizado pela presença de formas bastante dissecadas por ação fluvial, inúmeras colinas no formato de "meias laranjas" e fundos de vales de largura variável (ALVES, 2015; MARCHI et al., 2005; PRADO et al., 2018; ROCHA e FIALHO, 2010), conferindo ao estudo local do clima grande complexidade na determinação dos fatores condicionantes do comportamento dos elementos climáticos.

No momento da escolha da área que seria o objeto da pesquisa buscouse proporcionar uma aproximação com a realidade cotidiana dos pesquisadores. Tal medida visava trazer uma abordagem com maior significado e identificação por parte dos alunos no desenvolvimento do trabalho. A área de estudos foi delimitada tendo como referência a localização da escola e seu entorno (Figura 1). Ressalta-se o fato de que nessa porção da área urbana do município são desenvolvidas inúmeras atividades socioeconômicas que conferem grande dinamismo para essa localidade. Trata-se da principal área comercial do município, onde é observado grande fluxo diário de pessoas e veículos. 


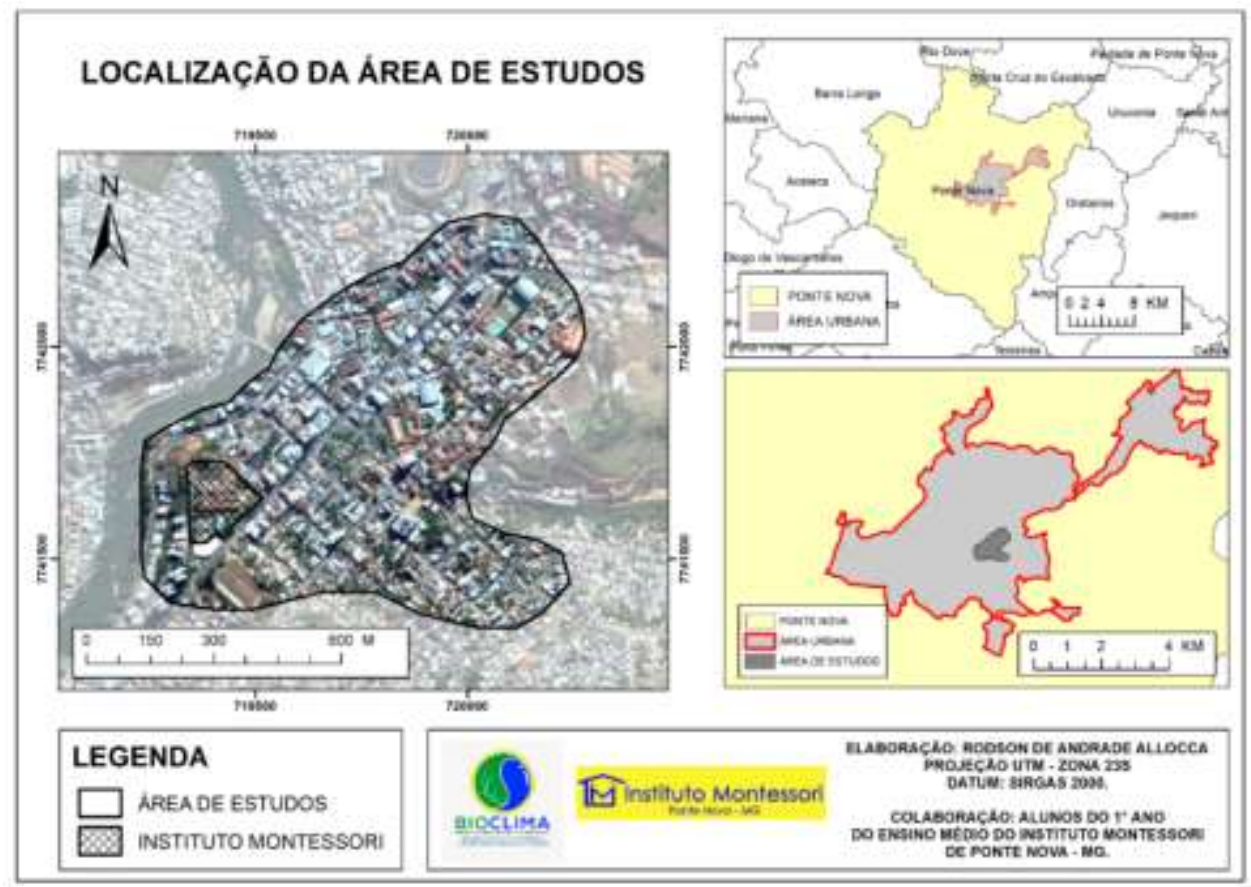

Figura 1 - Localização da área de estudo. Fonte: Elaborador pelo autor.

\section{AFERIÇÃO DE EQUIPAMENTOS}

Para o levantamento de dados térmicos foram adquiridos, com o apoio da Sociedade Educacional Montessori LTDA, dez termo-higrômetros digitais do modelo HTC - 2 (sem marca), semelhantes ao modelo ilustrado pela Figura 2. 0 equipamento possui um sensor interno e outro externo. Segundo especificações presentes na embalagem, o produto é capaz de efetuar registros de temperaturas compreendidas no intervalo entre $-10^{\circ} \mathrm{C}$ e $50^{\circ} \mathrm{C}$, com precisão de $+/-1^{\circ} \mathrm{C}$.

A turma era composta por trinta e seis alunos que foram organizados em dez grupos distintos e os equipamentos numerados numa sequência de 1 a 10 . Cada grupo ficou responsável por um equipamento.

Depois de serem definidos os grupos de alunos e seus respectivos equipamentos, os termo-higrômetros foram dispostos em uma bancada horizontal dentro do laboratório de ciências do Instituto Montessori (Figura 2). As janelas e portas do laboratório foram fechadas para que fossem evitadas interferências externas nos registros dos dados.

Durante 30 minutos, em intervalos de 2 em 2 minutos, cada grupo registrou os dados de temperatura de seu equipamento, totalizando 16 registros para cada termo-higrômetro, conforme pode ser observado na Figura 3. 


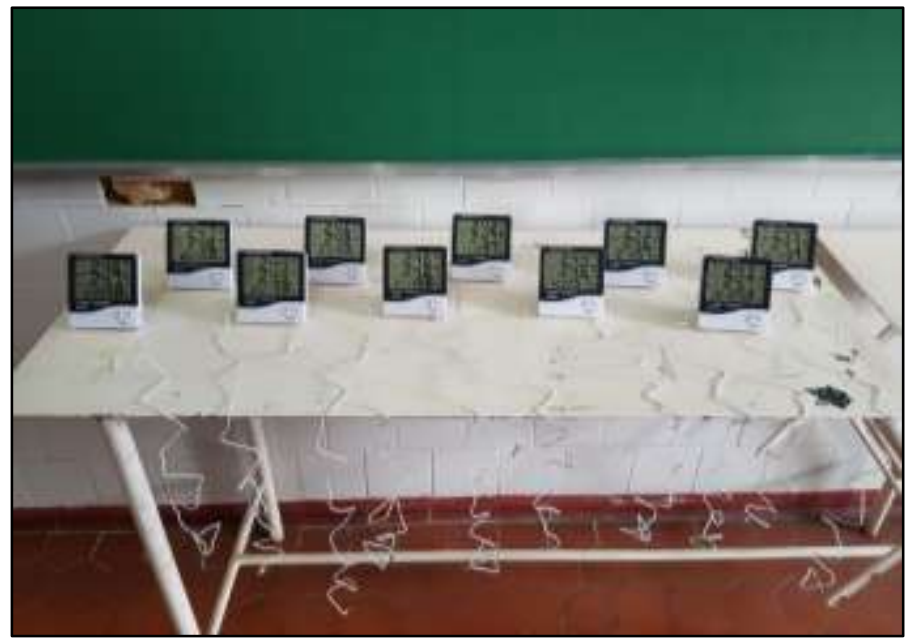

Figura 2 - Aferição dos equipamentos em laboratório. Fonte: Registro fotográfico efetuado pelo autor.

\begin{tabular}{|c|c|c|c|c|c|c|c|c|c|c|}
\hline \multicolumn{11}{|c|}{ COMPARAÇÃO DOS REGISTROS PARA AFERIÇÃO } \\
\hline EQUIPAMENTO & 1 & 2 & 3 & 4 & 5 & 6 & 7 & 8 & 9 & 10 \\
\hline HORA & $\mathrm{T}^{\circ} \mathrm{C}$ (OUT) & $\mathrm{T}^{\circ} \mathrm{C}$ (OUT) & $\mathrm{T}^{\circ} \mathrm{C}$ (OUT) & $\mathrm{T}^{\circ} \mathrm{C}$ (OUT) & $\mathrm{T}^{\circ} \mathrm{C}$ (OUT) & $\mathrm{T}^{\circ} \mathrm{C}$ (OUT) & $\mathrm{T}^{\circ} \mathrm{C}$ (OUT) & $\mathrm{T}^{\circ} \mathrm{C}$ (OUT) & $\mathrm{T}^{\circ} \mathrm{C}$ (OUT) & $\mathrm{T}^{\circ} \mathrm{C}$ (OUT) \\
\hline $10: 10$ & 24,7 & 24,7 & 24,9 & 24,9 & 24,8 & 24,7 & 24,6 & 24,8 & 24,7 & 24,7 \\
\hline $10: 12$ & 24,7 & 24,8 & 24,8 & 24,8 & 24,8 & 24,8 & 24,6 & 24,7 & 24,8 & 24,8 \\
\hline $10: 14$ & 24,8 & 24,8 & 25 & 25 & 24,9 & 24,9 & 24,8 & 24,8 & 24,9 & 24,9 \\
\hline $10: 16$ & 25 & 24,9 & 25,1 & 25,1 & 25,1 & 25 & 24,8 & 25 & 25 & 25 \\
\hline $10: 18$ & 25,1 & 24,9 & 25,2 & 25,1 & 25,1 & 25 & 24,9 & 25 & 25 & 25 \\
\hline $10: 20$ & 25 & 25,1 & 25 & 25 & 25 & 24,9 & 24,8 & 24,8 & 24,9 & 24,9 \\
\hline $10: 22$ & 24,8 & 24,8 & 24,8 & 24,9 & 24,8 & 24,9 & 24,8 & 24,8 & 24,9 & 24,8 \\
\hline $10: 24$ & 24,9 & 24,9 & 25 & 25 & 24,9 & 24,9 & 24,8 & 24,9 & 24,9 & 24,9 \\
\hline $10: 26$ & 24,9 & 24,4 & 25 & 24,9 & 24,9 & 24,9 & 24,7 & 24,8 & 24,9 & 24,9 \\
\hline $10: 28$ & 25 & 25 & 25,1 & 25 & 25 & 25 & 24,8 & 24,9 & 25 & 24,8 \\
\hline $10: 30$ & 25 & 25,1 & 25,1 & 25,1 & 25,1 & 25 & 24,8 & 24,9 & 25 & 25 \\
\hline $10: 32$ & 25,1 & 25,2 & 25,3 & 25,2 & 25,2 & 25,1 & 25 & 25,1 & 25,2 & 25,2 \\
\hline $10: 34$ & 25,2 & 25,3 & 25,2 & 25,3 & 25,3 & 25,1 & 25 & 25,1 & 25,2 & 25,2 \\
\hline $10: 36$ & 25,2 & 25,3 & 25,3 & 25,4 & 25,3 & 25,2 & 24,1 & 25,2 & 25,4 & 25,3 \\
\hline $10: 38$ & 25,1 & 25,2 & 25,2 & 25,3 & 25,2 & 25,1 & 25 & 25,1 & 25,3 & 25,1 \\
\hline $10: 40$ & 25,2 & 25,3 & 25,3 & 25,3 & 25,3 & 25,2 & 25 & 25 & 25,2 & 25 \\
\hline
\end{tabular}

Figura 3 - Dados registrados no procedimento de aferição dos equipamentos. Fonte: Organizado pelo autor.

Os dados registrados em laboratório foram submetidos a um procedimento de aferição para a apuração dos desvios nos valores de temperatura de cada equipamento, com base em Danni-Oliveira (2002).

Inicialmente, foi calculada a média de registros para cada horário. Após o cálculo das médias, utilizando a Equação 1, foram apurados os desvios para cada equipamento nos diferentes horários de registro.

$$
D_{X}=L_{X}-M
$$

Onde:

$D_{X}$ é o desvio da temperatura registrada pelo equipamento;

$L_{X}$ é a temperatura registrada pelo equipamento específico; 
$M$ é a média dos registros ${ }^{1}$ no horário específico de observação.

Com a aplicação da equação, foi possível calcular a média dos desvios de cada equipamento, conforme pode ser observado na Figura 4.

\begin{tabular}{|c|c|c|c|c|c|c|c|c|c|c|c|}
\hline & \multirow[b]{2}{*}{ EQUAPAMENTO } & \multicolumn{10}{|c|}{ DESVIOS } \\
\hline & & 1 & 2 & 3 & 4 & 5 & 6 & 7 & 8 & 9 & 10 \\
\hline $\begin{array}{l}\text { MÉDIAS TERMMICAS } \\
\text { POR HORÁRIO (T'C) }\end{array}$ & HORÁRIO DE REGISTRO & & & & & & & & & & \\
\hline 24,75 & $10: 10$ & $-0,05$ & -0.05 & 0,15 & 0,15 & 0,05 & $-0,05$ & $-0,15$ & 0,05 & $-0,05$ & $-0,05$ \\
\hline 24,76 & 10212 & 0,06 & 0,04 & 0,04 & 0,04 & 0,04 & 0,04 & 0,16 & $-0,06$ & 0,04 & 0,04 \\
\hline 24,83 & $10: 14$ & $-0,08$ & 0.08 & 0,12 & 0,12 & 0,02 & 0,02 & $-0,03$ & 0,08 & 0,02 & 0,02 \\
\hline 25 & $10: 16$ & 0 & 0,1 & 0,1 & 0,1 & 0,1 & 0 & 0.2 & a & 0 & 0 \\
\hline 25,03 & $10: 18$ & 0,07 & $-0,13$ & 0,17 & 0,07 & 0,07 & $-0,03$ & $-0,13$ & $-0,03$ & $-0,03$ & $-0,03$ \\
\hline 24,94 & $10: 20$ & 0,06 & 0,16 & 0.06 & 0,06 & 0.06 & $-0,04$ & $-0,14$ & $-0,14$ & $-0,04$ & $-0,04$ \\
\hline 24,85 & $10: 22$ & $-0,03$ & $-0,03$ & $-0,03$ & 0,07 & $-0,03$ & 0,07 & $-0,05$ & $-0,03$ & 0,07 & $-0,03$ \\
\hline 24,91 & 10.24 & $-0,01$ & -0.01 & 0.09 & 0,09 & -0.01 & $-0,01$ & $-0,11$ & -0.01 & $-0,01$ & $-0,01$ \\
\hline 24,83 & 10.26 & 0,07 & $-0,43$ & 0,17 & 0,07 & 0,07 & 0,07 & $-0,13$ & $-0,03$ & 0,07 & 0,07 \\
\hline 24,96 & 10.28 & 0,04 & 0,04 & 0,14 & 0,04 & 0,04 & 0,04 & $-0,16$ & $-0,06$ & 0,04 & $-0,16$ \\
\hline 25,01 & $10: 30$ & $-0,01$ & 0,09 & 0.09 & 0,09 & 0,09 & 0,01 & $-0,21$ & 0.11 & $-0,01$ & 0,01 \\
\hline 25,16 & $10: 32$ & 0,06 & 0,04 & 0,14 & 0,04 & 0,04 & $-0,06$ & $-0,16$ & 0,06 & 0,04 & 0,04 \\
\hline 25,19 & $10: 34$ & 0,01 & 0,11 & 0,01 & 0,11 & 0,11 & $-0,09$ & $-0,19$ & $-0,09$ & 0,01 & 0,01 \\
\hline 25,17 & 10.36 & 0,09 & 0,13 & 0.13 & 0,23 & 0,13 & 0.03 & -1.07 & 0,09 & 0,29 & 0,13 \\
\hline 25,16 & $10: 38$ & $-0,06$ & 0,04 & 0,04 & 0,14 & 0,04 & $-0,06$ & $-0,16$ & $-0,06$ & 0,14 & $-0,06$ \\
\hline \multirow[t]{2}{*}{25,18} & $10: 40$ & 0,02 & 0,12 & 0,12 & 0,12 & 0,12 & 0,02 & 0,18 & 0,18 & 0,02 & $-0,18$ \\
\hline & $\begin{array}{l}\text { MÉDIA DOS DESVIOS POR } \\
\text { EQUIPAMENTO }\end{array}$ & 0,0 & 0,0 & 0,1 & 0,1 & 0,1 & 0,0 & $-0,2$ & 0,1 & 0,0 & 0.0 \\
\hline
\end{tabular}

Figura 4 - Cálculo das médias dos desvios. Fonte: Organizado pelo autor.

As médias dos desvios observadas para cada equipamento foram utilizadas na correção dos valores registrados em campo para que, dessa forma, houvesse uma compensação das possíveis variações nas temperaturas registradas em decorrência da utilização dos diferentes equipamentos.

Esse procedimento de aferição foi importante para que os valores mensurados em campo pudessem ser utilizados e, desse modo, validar as possíveis diferenças térmicas encontradas na espacialização do campo térmico da área pesquisada.

\section{ESTRUTURAÇÃO DA COLETA DE DADOS}

Dando prosseguimento ao trabalho, buscou-se definir os pontos onde as temperaturas seriam coletadas e com o auxílio do Google Earth, os alunos delimitaram a área da pesquisa. Dentro do recorte espacial, buscando abarcar diferentes contextos geoambientais e geourbanos, foram definidos os dez pontos de coleta (Figura 5).

\footnotetext{
${ }^{1}$ Especificamente para a pesquisa em questão, trata-se da média dos registros efetuados pelos dez equipamentos utilizados em cada horário.
} 


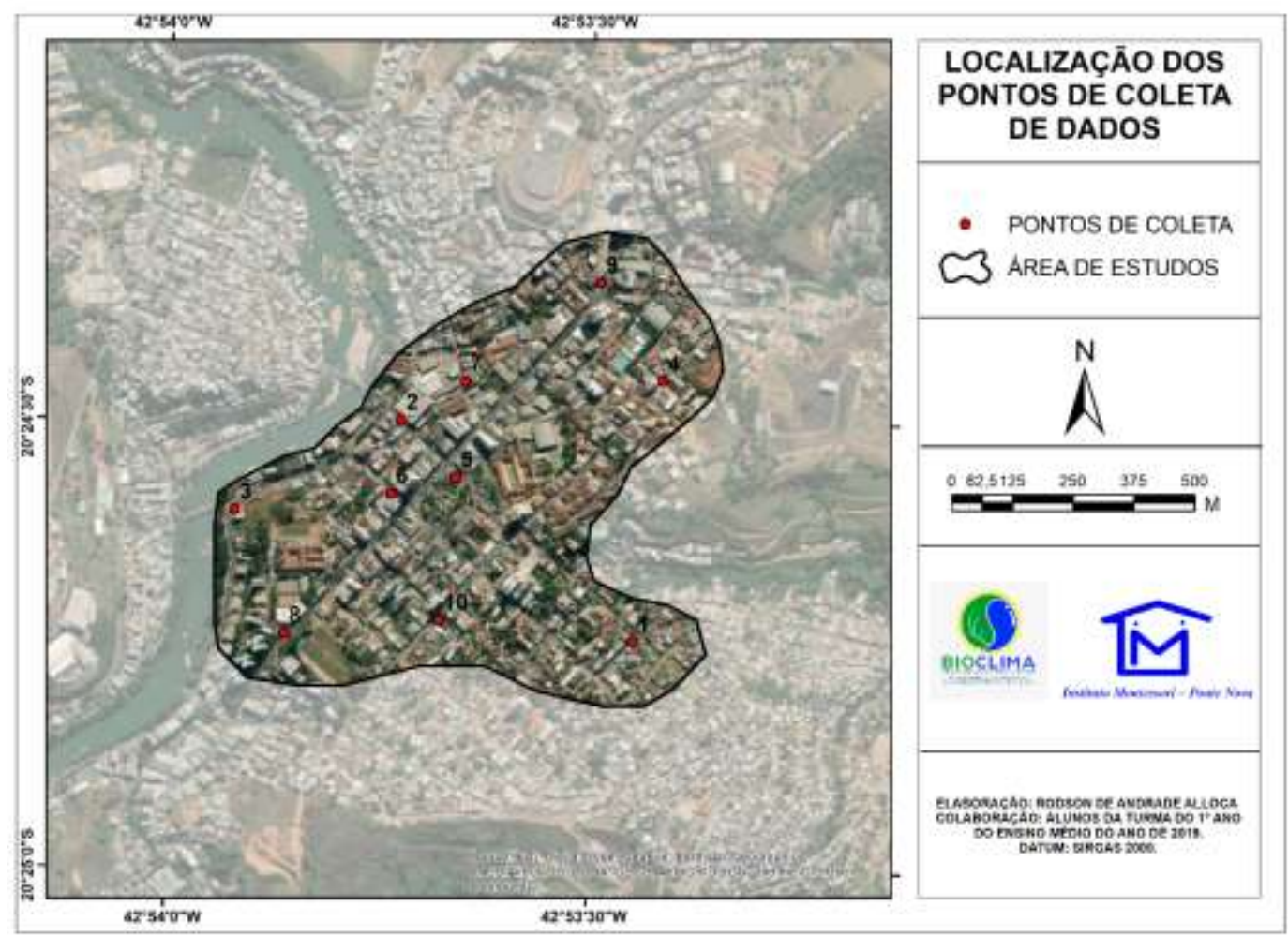

Figura 5 - Definição dos pontos de coleta. Fonte: Elaborado pelo autor.

No momento seguinte, baseado em Allocca (2018), Correa (2014) e Oliveira (2019), foi solicitado aos alunos que fizessem a caracterização de cada ponto de coleta (Tabela 1). As informações de coordenadas geográficas e altitude dos pontos de coleta foram obtidas através do aplicativo C7 GPS Dados, desenvolvido pelo laboratório de Geomática da Universidade Federal de Santa Maria (UFSM), disponível para download no Google Play Store.

A caracterização dos pontos de coleta foi uma etapa de grande importância, pois, posteriormente em sala de aula, foi possível uma problematização sobre as diferentes estruturas urbanas e, preliminarmente, dar início a uma discussão sobre quais as possíveis implicações dessas características observadas nos diferentes pontos de coleta na conformação do campo térmico. Essa problematização seria confrontada com os dados coletados e a espacialização das informações. 
Tabela 1 - Caracterização dos pontos de coleta

\begin{tabular}{|c|c|c|c|c|c|}
\hline \multicolumn{6}{|c|}{ Caracterização dos pontos de coleta } \\
\hline Ponto & Id & Características & Imagem & Coordenadas & $\begin{array}{l}\text { Altitude } \\
(m)\end{array}$ \\
\hline 1 & $\begin{array}{l}\text { INÍCIO DA } \\
\text { AV. } \\
\text { OTÁVIO DR. } \\
\text { SOARES } \\
\text { (ESQUINA } \\
\text { ABAIXO DO } \\
\text { CEMITÉRIO } \\
\text { DE } \\
\text { PALMEIRAS) }\end{array}$ & 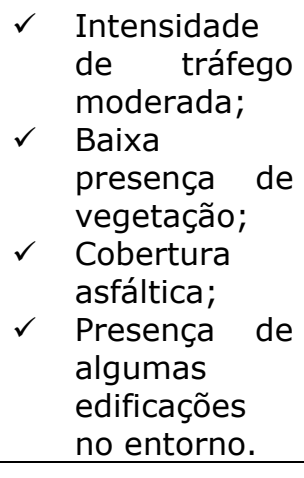 & & $\begin{array}{l}X=720092 \\
Y=7741470\end{array}$ & 424 \\
\hline 2 & $\begin{array}{lr}\text { AV. } & \text { DR. } \\
\text { OTÁVIO } & \\
\text { SOARES } & \text { EM } \\
\text { FRENTE } & \text { AO } \\
\text { SUPERMERCA } \\
\text { DO BAHAMAS }\end{array}$ & 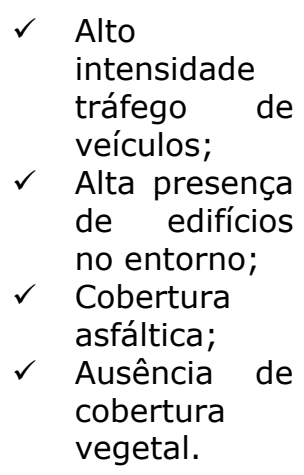 & & $\begin{array}{l}X=719615 \\
Y=7741927\end{array}$ & 402 \\
\hline 3 & $\begin{array}{l}\text { PONTILHÃO } \\
\text { DE FERRO }\end{array}$ & 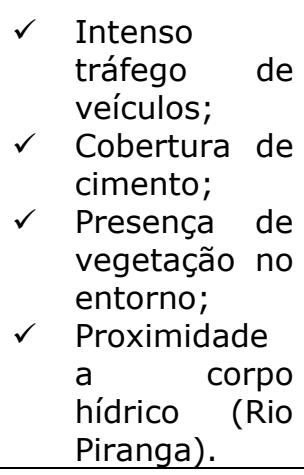 & & $\begin{array}{l}X=719271 \\
Y=7741743\end{array}$ & 416 \\
\hline 4 & $\begin{array}{ll}\text { ESQUINA DA } \\
\text { RUA CARLOS } \\
\text { MARQUES } \\
\text { COM A RUA } \\
\text { FARM. } \\
\text { ANTÔNIO } \\
\text { VIEIRA } \\
\text { LANNA }\end{array}$ & 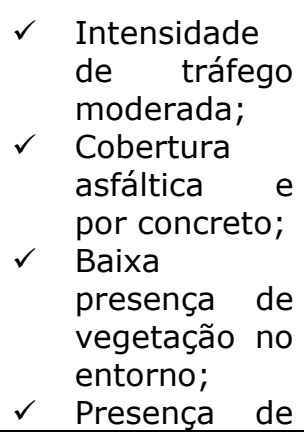 & & $\begin{array}{l}X=720155 \\
Y=7742006\end{array}$ & 417 \\
\hline
\end{tabular}




\begin{tabular}{|c|c|c|c|c|c|}
\hline & & edificações. & & & \\
\hline 5 & $\begin{array}{l}\text { PRAÇA DE } \\
\text { PALMEIRAS }\end{array}$ & 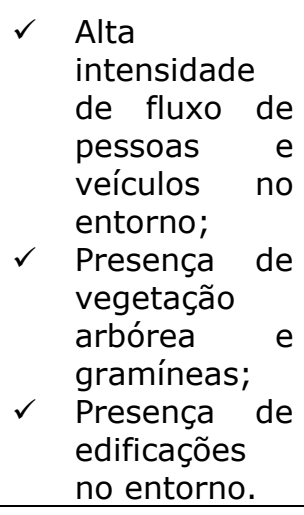 & $8 x-1=$ & $\begin{array}{l}X=719727 \\
Y=7741809\end{array}$ & 414 \\
\hline 6 & $\begin{array}{l}\text { MUNDIAL } \\
\text { CALÇADOS }\end{array}$ & $\begin{array}{ll}\checkmark & \text { Alta } \\
& \text { intensidade } \\
& \text { de tráfego; } \\
\checkmark & \text { Não há } \\
& \text { presença de } \\
& \text { vegetação } \\
& \text { arbórea; } \\
\checkmark & \text { Cobertura } \\
\text { asfáltica; } \\
\checkmark \quad \text { Alta presença } \\
\text { de } \\
\text { edificações e } \\
\text { comércios. }\end{array}$ & 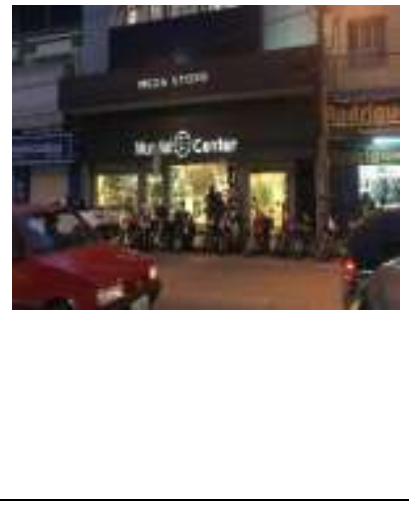 & $\begin{array}{l}X=719593 \\
Y=7741776\end{array}$ & 406 \\
\hline 7 & $\begin{array}{l}\text { SUPERMERCA } \\
\text { DO POUPY }\end{array}$ & 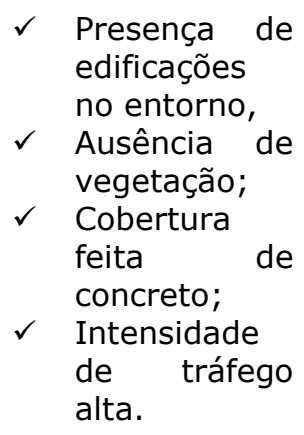 & 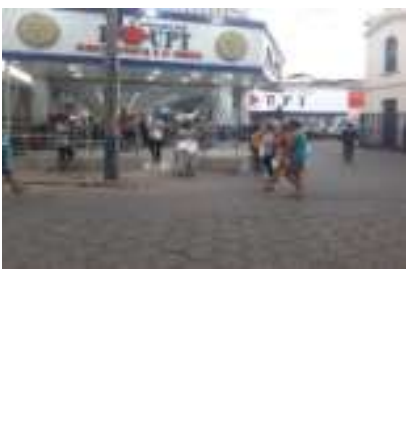 & $\begin{array}{l}X=719747 \\
Y=7742007\end{array}$ & 397 \\
\hline
\end{tabular}




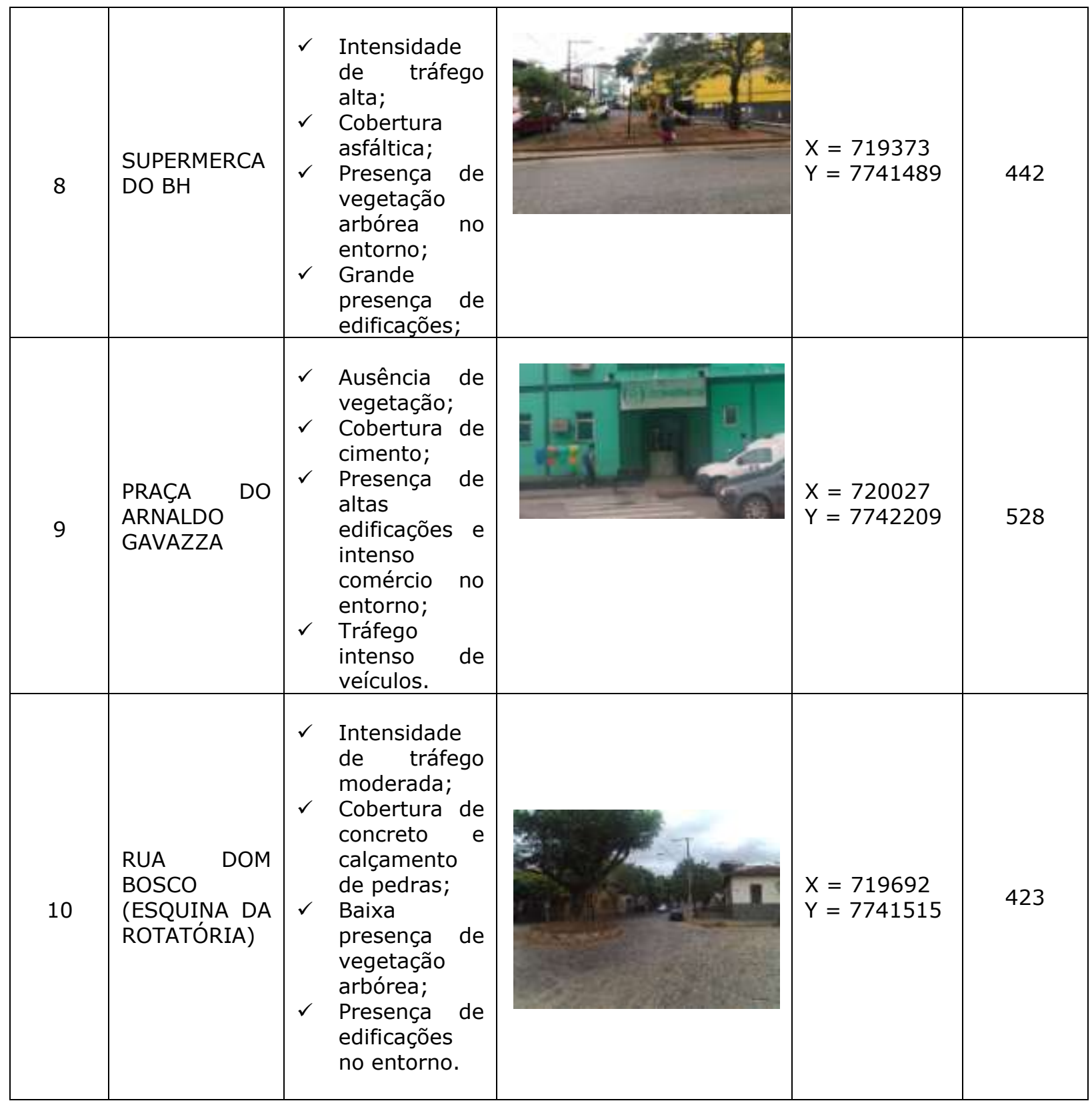

Fonte: Organizado pelo autor.

\section{COLETA DE DADOS}

Para a realização da coleta de dados foram confeccionados pelos alunos miniabrigos para os sensores externos dos termo-higrômetros (Figura 6), procedimento também adotado por Fialho (2009), Correia (2014), Allocca (2018) e Oliveira (2018). Os miniabrigos foram construídos em material PVC (Policloreto de Vinila) e envoltos em papel alumínio para reduzir o efeito da radiação solar direta.

No dia 23 de novembro de 2019, às 09h00min, foi realizada a coleta simultânea de dados térmicos pelos diferentes grupos de alunos. Os dados 
coletados foram organizados e corrigidos a partir dos procedimentos de aferição antes de serem espacializados.

Posteriormente, foi aplicado um questionário, por meio da plataforma Google Forms, com intuito de levantar informações sobre a percepção dos alunos sobre o campo térmico, objetivando confrontá-la com os resultados obtidos pelo levantamento em campo. Isto porque o espaço do entorno da escola é o ambiente de vivência desses alunos.

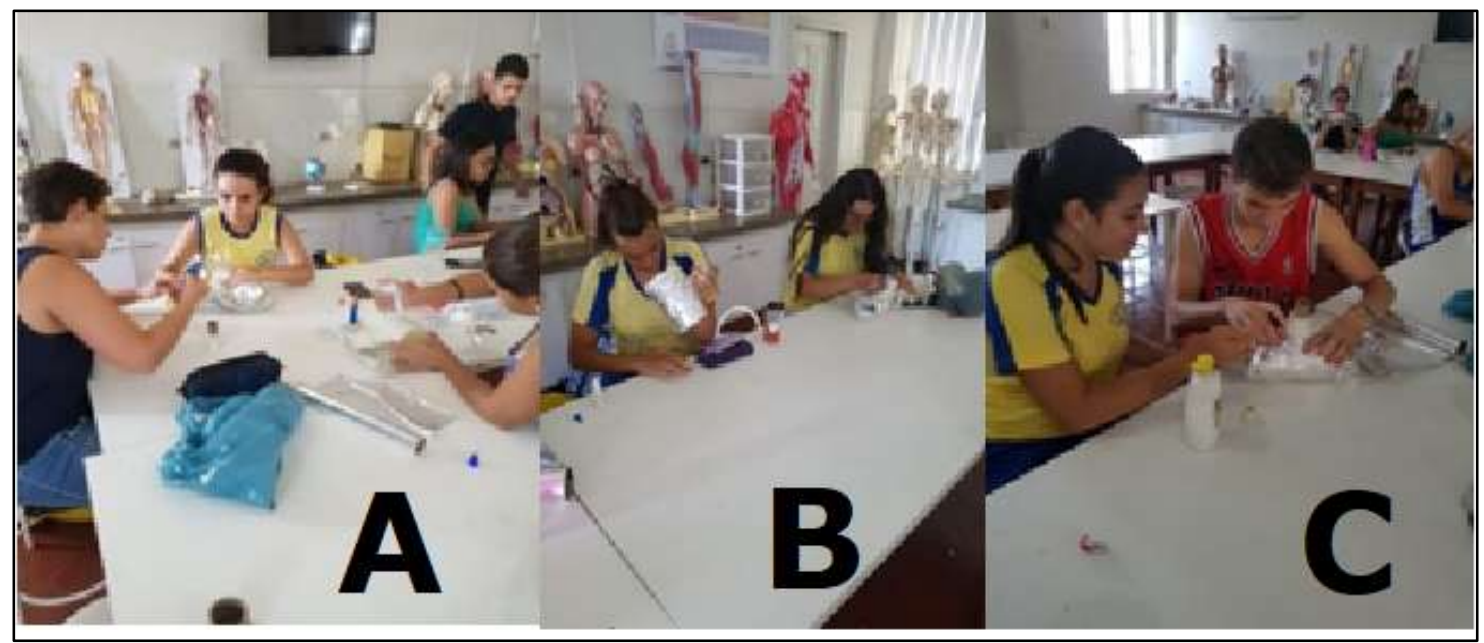

Figura 6 - Alunos em processo de confecção dos abrigos de proteção dos sensores de temperatura, divididos em três grupos. Fonte: Registro fotográfico realizado pelo autor.

\section{RESULTADOS E DISCUSSÃO}

Segundo Fialho (2019, p. 63),

Compreender a configuração da temperatura do ar, no meio urbano, é mais do que relatar quantitativamente as diferenças entre localidades distintas. Os dados obtidos são indícios das interações entre sociedade e natureza impressas na atmosfera. Assim, os elementos climáticos mensurados, interpretados à luz dos conceitos da ciência geográfica são lentes que permitem o observador entender a organização do espaço e parte de uma realidade objetivada.

Nesse sentido, a realização deste trabalho de campo, junto com os alunos do Ensino Médio, permite que a linguagem científica seja incorporada ao ambiente escolar, a fim de despertar o interesse pela ciência, por meio das etapas de organização, estruturação e levantamento dos dados, que foram trabalhados, conforme Fialho (2014) em ambiente de Sistema de Informações Geográficas (SIG) e que segundo Oliva e Fonseca (2011) por sua agilidade e potencialidade na espacialização dos dados possibilitam sair da abstração para o concreto.

Trabalhando com os mapas os alunos puderam melhor compreender o espaço geográfico em análise. Segundo Simielli (1999) os mapas permitem ter 
domínio espacial e fazer a síntese dos fenômenos que ocorrem em determinado espaço. Os produtos gerados pela espacialização dos dados coletados foram apresentados aos estudantes e utilizados na construção de conhecimento relativo ao tema abordado no âmbito da pesquisa em curso.

Os dados de temperatura do ar coletados (Figura 7), após passarem por um procedimento de correção que levou em consideração os desvios específicos de cada equipamento, foram utilizados para gerar o mapeamento do campo térmico da área da pesquisa através da interpolação de dados. Optou-se pelo método Inverse Distance Weighting (IDW), procedimento também adotado por Correa (2014) e Allocca (2018).

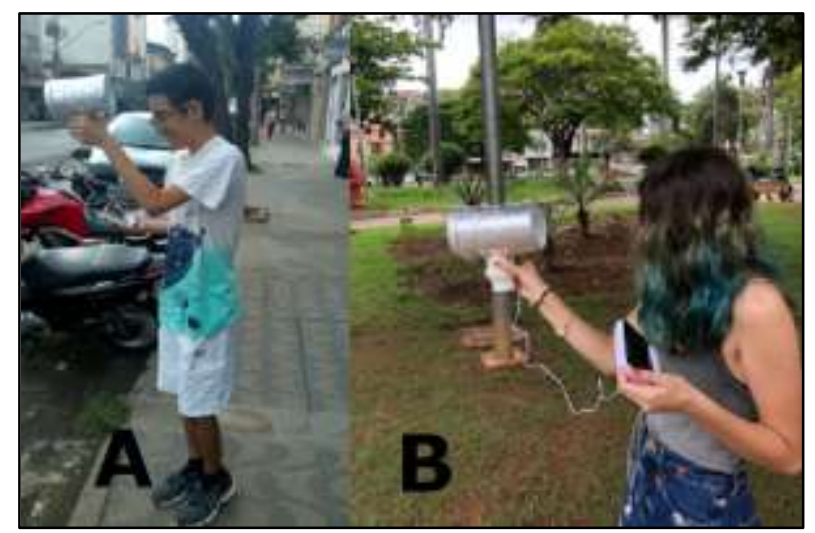

Figura 7 - Alunos em momento de registro de temperatura do ar no Ponto 2 (A) e no Ponto 5 (B). Fonte: Registro fotográfico realizado pelos alunos.

O município de Ponte Nova não possui uma estação meteorológica oficial e, por essa razão, devido ao fato de os termo-higrômetros não terem sido calibrados com base nos dados registrados e disponibilizados por uma estação oficial, optou-se por trabalhar com as diferenças térmicas e não os valores absolutos de temperatura do ar. Nesse sentido, a aferição dos equipamentos foi fundamental para validar os valores térmicos obtidos nos diferentes pontos de coleta pelos diferentes equipamentos e, desse modo, foi possível efetuar uma comparação entre eles.

As diferenças térmicas encontras (Tabela 2) foram evidenciadas através do mapeamento do campo térmico, conforme pode ser observado na Figura 8. No Ponto 8 (em frente ao Supermercado $\mathrm{BH}$ ) foi registrada a menor temperatura e no Ponto 1 (no início da Av. Dr. Otávio Soares) foi registrada a maior. A diferença de temperatura entre esses dois pontos foi de $3,7^{\circ} \mathrm{C}$. Podemos destacar também o Ponto 3 que, na comparação com o Ponto 8 (de menor temperatura), apresentou uma diferença de $3,6^{\circ} \mathrm{C}$. 
Tabela 2 - Diferenças térmicas

\begin{tabular}{|l|c|l|}
\multicolumn{1}{|c|}{ NOME DO PONTO } & PONTO & $\begin{array}{l}\text { Dif. } \\
\left(\mathbf{T}^{\circ} \mathbf{C}\right)\end{array}$ \\
\hline $\begin{array}{l}\text { INÍCIO DA AV. DR. OTÁVIO SOARES (ESQUINA ABAIXO DO } \\
\text { CEMITÉRIO DE PALMEIRAS) }\end{array}$ & 1 & 3,7 \\
\hline SUPERMERCADO BAHAMAS & 2 & 1,3 \\
\hline PONTILHÃO DE FERRO & 3 & 3,6 \\
\hline $\begin{array}{l}\text { ESQUINA DA RUA CARLOS MARQUES COM A RUA FARM. ANTÔNIO } \\
\text { VIEIRA D. LANNA }\end{array}$ & 4 & 2,7 \\
\hline PRAÇA DE PALMEIRAS & 5 & 1 \\
\hline MUNDIAL CALÇADOS & 6 & 1,4 \\
\hline SUPERMERCADO POUPY & 7 & 2,3 \\
\hline SUPERMERCADO BH & 8 & 0 \\
\hline PRAÇA DO ARNALDO GAVAZZA & 9 & 1,7 \\
\hline RUA DOM BOSCO (ESQUINA DA ROTATÓRIA) & 10 & 0,1 \\
\hline
\end{tabular}

Fonte: Organizado pelo autor.

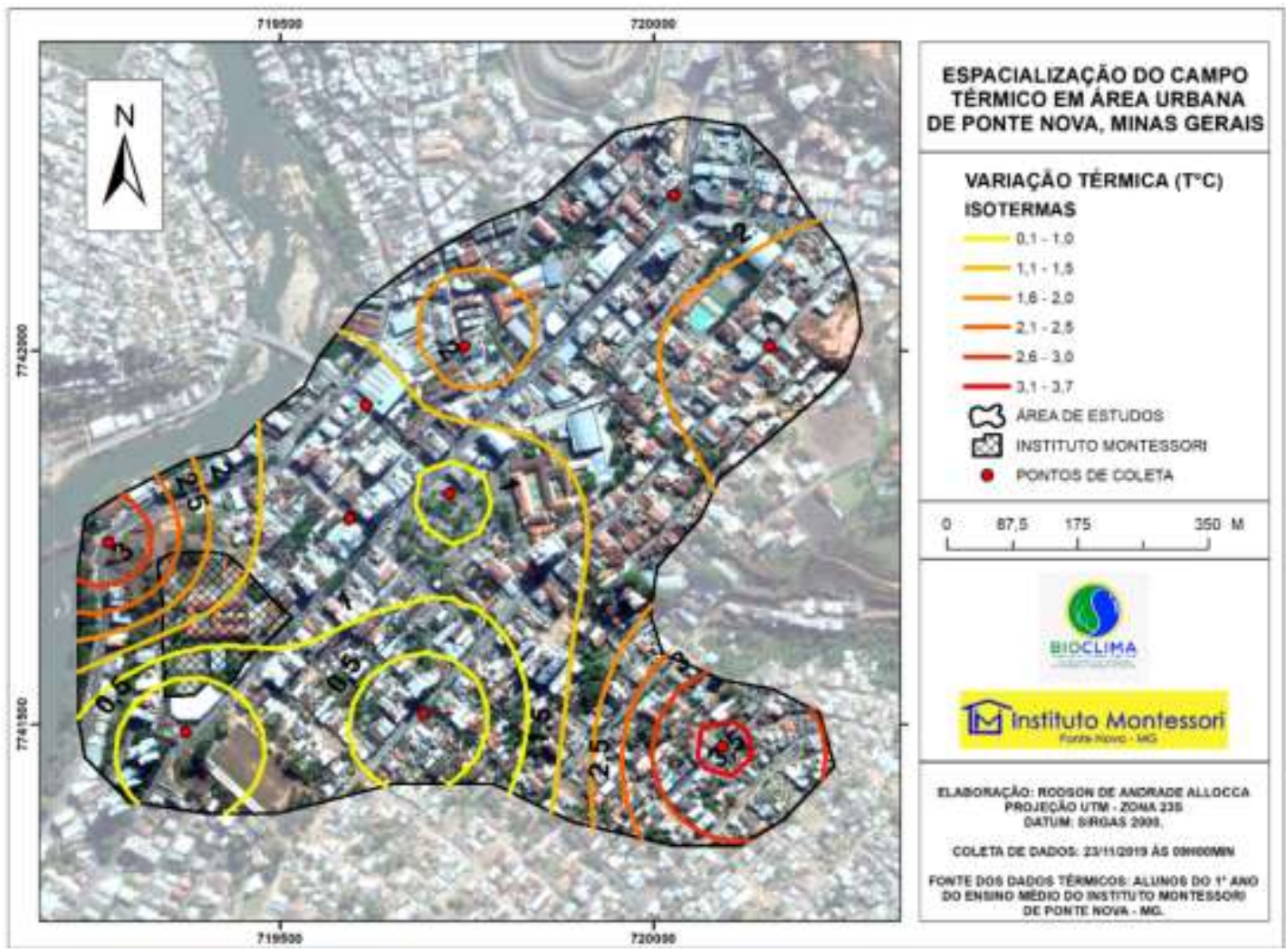

Figura 8 - Espacialização do campo térmico. Fonte: Elaborado pelo autor.

A diversidade das características geourbanas e geoambientais encontradas nos pontos é um fator a ser considerado na compreensão da espacialização do campo térmico e da variação térmica registrada (Figura 9). Contudo, não é possível determinar causas para maior aquecimento ou 
resfriamento levando em consideração apenas essas características. Quando, juntamente com os alunos, foi feita uma comparação entre os dois pontos onde foram registradas as maiores temperaturas, não houve consenso na definição de um padrão de semelhanças que pudesse justificar tal comportamento.

O Ponto 1 (de maior aquecimento) está situado a uma altitude de aproximadamente 424 metros, em uma vertente de encosta. Já o Ponto 3 (segundo mais aquecido) situa-se em uma cota altimétrica de aproximadamente 416 metros, às margens do Rio Piranga, onde o relevo é plano. Outra característica divergente é a variação da intensidade do tráfego, que no Ponto 3 se apresenta maior. Em ambos a cobertura do solo é asfáltica e não há grande presença de edificações em seu entorno. Ao analisar e comparar as características dos dois pontos, percebe-se, como foi indicado anteriormente, que não há um padrão evidente, demandando um maior aprofundamento no âmbito da pesquisa.

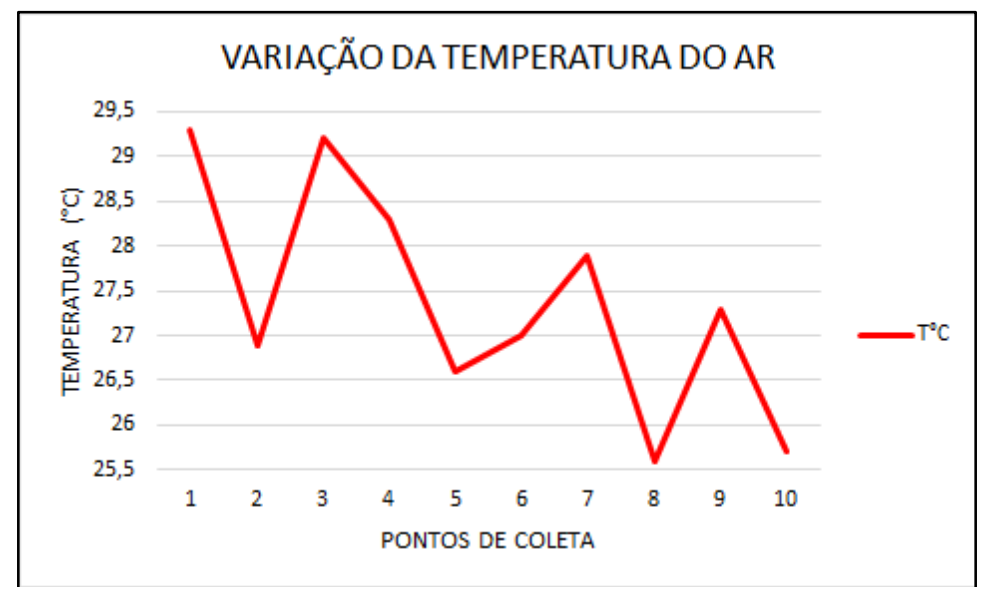

Figura 9 - Variação dos valores térmicos. Fonte: Organizado e elaborado pelo autor.

Na análise sobre o campo térmico da área urbana de Ponta Nova, Allocca (2018) indica que a definição da influência dos fatores geourbanos e geoambientais no comportamento das temperaturas observadas é algo complexo, sobretudo em função das características do relevo local.

Nesse contexto, a escola está inserida em uma área onde os valores das diferenças térmicas oscilaram em aproximadamente $2^{\circ} \mathrm{C}$ e também não foi possível atestar no decurso da pesquisa as causas dessa variação.

Como parte da pesquisa, antes da obtenção dos resultados da espacialização dos dados térmicos, foi aplicado um questionário junto aos alunos. Nesse questionário, os participantes deveriam responder a quatro perguntas. As perguntas objetivavam fazer o levantamento da percepção que os estudantes tinham em relação ao campo térmico na área pesquisada. Basicamente, a partir das respostas obtidas, os alunos indicavam qual seria o ponto mais aquecido e qual seria o menos aquecido. Um total de vinte e quatro questionários foi respondido e nas Figuras 10 e 11 é possível ver uma síntese das informações coletadas.

De acordo com o questionário, 36\% (9 votos) dos alunos participantes acreditava que o Ponto 6 seria o mais aquecido. Já o Ponto 3, foi apontado como ponto menos aquecido por $32 \%$ ( 8 votos) dos alunos. 
O levantamento de informações através do questionário respondido pelos alunos foi utilizado como um instrumento na pesquisa, uma vez que, os resultados baseavam-se na vivência e na percepção que cada um possuía das características da área analisada. Os resultados obtidos em campo na coleta de dados puderam ser confrontados com a observação empírica e, de certa forma, subjetiva elaborada pelos estudantes.

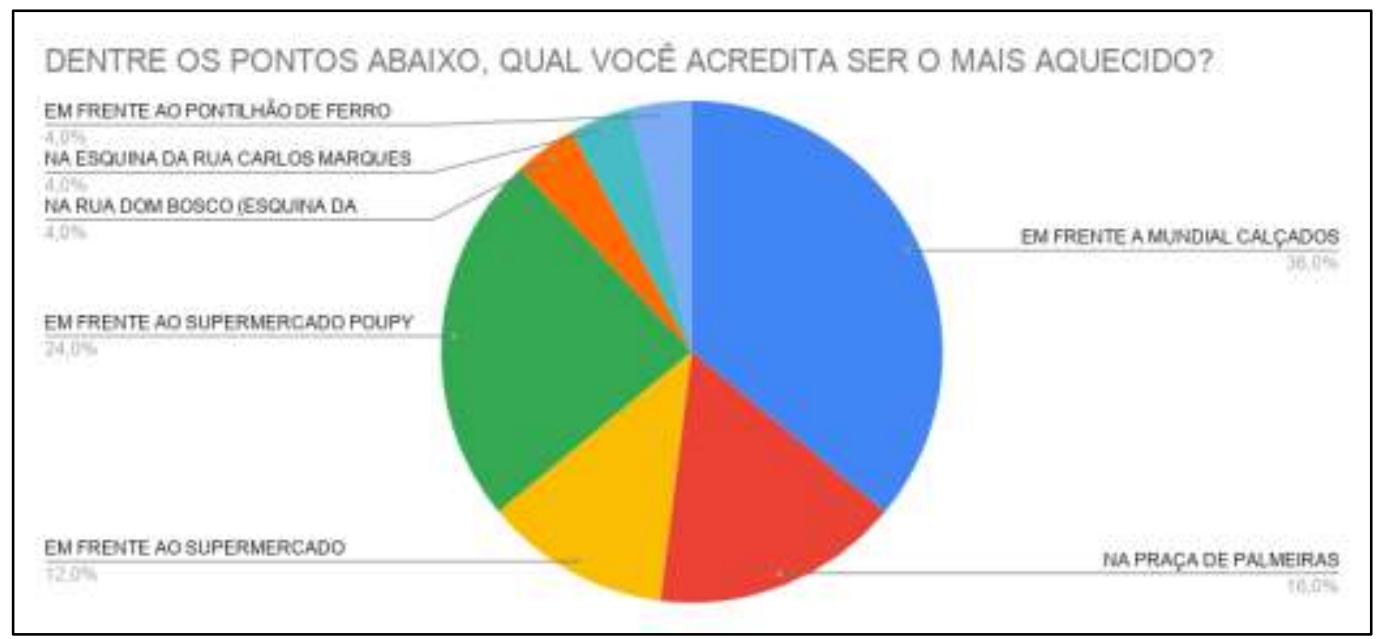

Figura 10 - Percepção dos alunos sobre o ponto mais aquecido. Fonte: Google Forms. Organizado pelo autor.

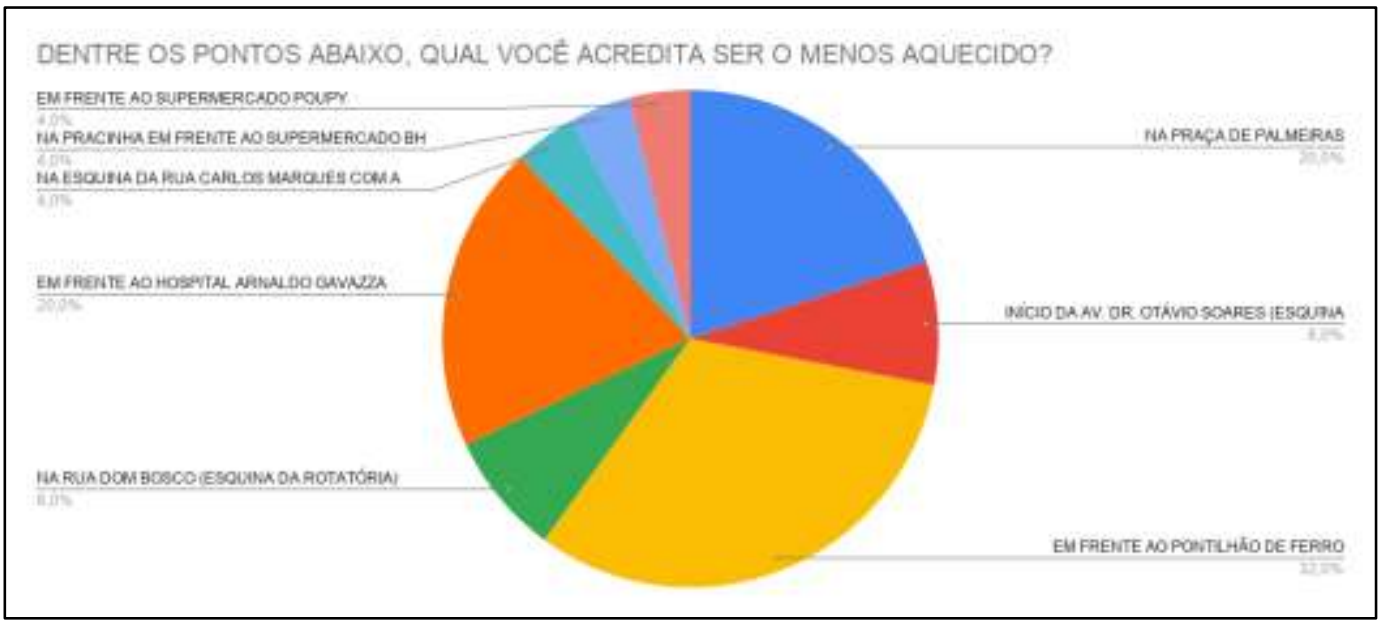

Figura 111 - Percepção dos alunos sobre o ponto menos aquecido. Fonte: Google Forms. Organizado pelo autor.

Nessa confrontação, os resultados mostraram-se divergentes, pois o empirismo não foi confirmado pelos fatos da pesquisa. Os pontos indicados pelos alunos como mais aquecidos ou menos aquecidos não foram coincidentes. De maneira geral, os alunos ficaram surpreendidos pelos resultados e puderam perceber a importância do levantamento de dados.

O trabalho foi desenvolvido no último trimestre do ano letivo de 2019 e, infelizmente, em função do calendário escolar não houve tempo hábil para que as discussões sobre os resultados pudessem ser aprofundadas. 
Contudo, é oportuno destacar o fato de que a prática desenvolvida foi de grande relevância para a compreensão do tema. Ao longo do desenvolvimento do trabalho, foram perceptíveis a participação, o envolvimento e o empenho dos estudantes. Tal fato ressalta ainda mais a importância de que os professores busquem alternativas para proporcionar experiências educacionais que extrapolem o formato tradicional das aulas. Como Melo et al. (2018, p. 47) afirma, "os educadores nos dias atuais têm que pensar novas metodologias pedagógicas para mostrar aos alunos que o conhecimento geográfico é um instrumento social e que faz parte de sua realidade". Muito embora, esse formato não seja observado como uma característica da docência que se concretiza na grande maioria das escolas brasileiras.

Além disso, o trabalho em questão, buscou promover a vivência de uma experiência didático-pedagógica, no ensino da climatologia, que conforme Collischonn (2002) observou, a investigação instrumental exercitou habilidades operatórias, junto aos discentes, que não podem ser esquecidas, tais como:

- Observação - Ato de fixar-se e pensar sobre determinada coisa.

- Comparação - Inclui a abstração.

- Interpretação - Busca a explicação do sentido.

- Imaginação - Procura criar a combinação de ideias.

- Hipóteses - Conjecturas que se concebe, a partir da análise.

Este trabalho destaca a necessidade de valorização da concepção didática baseada na experimentação no ensino de climatologia, pois segundo Lima (2006) em grande parte, a experiência didática tem demonstrado que a leitura e a interpretação de dados e informações fornecidas pela meteorologia não garantem a apreensão do conhecimento relacionado à climatologia, pois o aluno dificilmente reconstrói o processo da descoberta, elaboração e utilização dos instrumentos que dão origem a estes dados se não aprender como é o seu funcionamento e não acompanhar um levantamento de dados. Normalmente ocorre certa mitificação da etapa de medição dos fenômenos.

Principalmente, em um contexto, onde o ser humano se encontra cada vez mais distante dos ciclos da natureza, conforme aponta Sennett (2003, p.117), o que gera uma superficialidade da sociedade moderna, ou afastamento dos ciclos naturais, que desorganiza o tempo (cronológico). Por conta disso, segundo Collischonn e Fialho (2007) as pessoas estão descomprometidas com a observação do tempo e das variações sazonais, pois segundo o ditado popular: Faça Sol, Faça Chuva vou trabalhar, demonstrando a independência das atividades humanas, em grande parte, das condições climáticas locais.

Além disso, a leitura do mapa sobre o campo térmico (Figura 8 ) segundo Smith (1989, p. 198) afirma que sua leitura nunca é uma atividade abstrata, sem finalidade, embora seja frequentemente estudada deste modo por pesquisadores e teóricos e, infelizmente, ainda seja ensinada deste modo para muitos aprendizes. Os leitores sempre leem algo, leem com uma finalidade; a leitura e sua rememorização sempre envolve emoções, bem como conhecimento e experiência. Katuta (2002) apresenta questões que podem auxiliar ao leitor no primeiro entendimento e compreensão no processo de leitura do mapa, conforme o Quadro 1. 
Quadro 1 - Questões que o mapa pode auxiliar o leitor a responder.

\begin{tabular}{|l|l|}
\hline O que? & $\begin{array}{l}0 \text { que está representado no mapa? Qual ou quais } \\
\text { fenômenos o mapa está representando? }\end{array}$ \\
\hline Onde? & Onde se localiza determinado fenômeno ou lugar? \\
\hline Quando? & Em que momento, ocorre a intensidade máxima ? \\
\hline Quanto? & Qual a diferença térmica apresentada? \\
\hline Em que ordem? & Como se configura o campo térmico? \\
\hline
\end{tabular}

Fonte: Katuta (2002, p. 173). Adaptado.

\section{CONSIDERAÇÕES FINAIS}

No cotidiano da prática docente, um dos maiores desafios é o de conseguir criar uma ligação, que se faz extremamente necessária, entre a ciência geográfica (ou a ciência de modo geral) e a vivência dos alunos. Silva e Cardoso (2019) indicam que é importante estabelecer uma inter-relação dos temas e conceitos escolares com a realidade. Dessa forma, a aprendizagem é potencializada por estar dotada de significado.

Esse artigo buscou, através de um relato de experiência, contribuir para a construção de alternativas que possam ser utilizadas no cotidiano escolar, objetivando romper com uma abordagem meramente teórica da Climatologia Geográfica e, mais especificamente, dos estudos de Clima Urbano.

No processo de ensino e aprendizagem os alunos aplicaram os conhecimentos teóricos no desenvolvimento de atividades práticas. Desse modo, a partir dos resultados obtidos foi possível a construção de um pensamento que partiu de uma abordagem empírica e avançou em direção a uma constatação embasada em fatos apurados de uma forma sistematizada e científica. Esse caminho percorrido foi extremamente importante para que os alunos pudessem ter a visão de como os conhecimentos geográficos podem ser aplicados de forma cotidiana.

A pesquisa apresentada teve como foco principal oportunizar aos alunos envolvidos uma experiência significativa. Nesse sentido, os resultados no levantamento do campo térmico, passam a ter importância secundária. O que não significa dizer que não tenham nenhuma importância. Pelo contrário, são fruto do trabalho e do comprometimento de dedicados alunos, o que é louvável.

Os resultados indicaram haver diferenças térmicas entre os pontos analisados. A maior diferença foi de $3,7^{\circ} \mathrm{C}$ entre o Ponto 8 e o Ponto 1 . Foi possível verificar também, através dos resultados, que dentro dos limites da escola existe uma variação térmica de aproximadamente $2,0^{\circ} \mathrm{C}$.

Em razão do calendário e das demandas pertinentes à rotina escolar, não foi possível aprofundar nas discussões das causas dessas diferenças encontradas. Podemos aproveitar esse fato para ilustrar uma das inúmeras barreiras que os professores precisam contornar em sua prática diária. Muitas 
vezes as atividades e projetos acabam sendo negligenciados por falta de tempo e até mesmo por uma "obrigação" de que os conteúdos curriculares tenham que ser trabalhados integralmente.

Em síntese, o desenvolvimento do trabalho foi importante no processo de ensino dos conteúdos da Climatologia Geográfica. Além disso, os alunos puderam ter contato com uma abordagem sistematizada o que para muitos talvez tenha significado uma aproximação com o "fazer científico". Na construção do conhecimento, possibilitou a superação do senso comum e uma maior concretude da Geografia, uma ciência que foi, em certa medida, experimentada de forma prática, superando as páginas dos livros didáticos sem perder sua essência teórica.

\section{AGRADECIMENTOS:}

A Sociedade Educacional Montessori LTDA pelo apoio e pela confiança no desenvolvimento do trabalho.

Aos queridos alunos do primeiro ano do ensino médio do ano de 2019 pelo envolvimento e pela dedicação no desenvolvimento da proposta de pesquisa. Sem vocês não seria possível. O sentimento é de gratidão!

\section{REFERÊNCIAS BIBLIOGRÁFICAS:}

AB'SÁBER, A. N. Os domínios de natureza no Brasil: Potencialidades paisagísticas. São Paulo: Ateliê Editora, 2003.

ALLOCCA, R. A. Análise do campo térmico na área urbana de Ponte Nova-MG. 2018. 177f. Dissertação (Mestrado em Geografia). Centro de Ciências Humanas e Naturais, Universidade Federal do Espírito Santo. Disponível em: <http://www.geografia.ufes.br/pt-br/pos-graduacao/PPGG/detalhes-datese?id=12778>. Acesso em: 30. Ago. 2020.

ALLOCCA, R. A.; FIALHO, E. S. O campo térmico no perímetro urbano de Ponte Nova-MG (Zona da Mata Mineira), em situações sazonais de verão e Inverno, no ano de 2017. Revista Brasileira de Climatologia, Curitiba-PR, v. 24, n. 15, p. 300-329, 2019. Disponível em: <https://revistas.ufpr.br/revistaabclima/article/view/60753>. Acesso em: 20 ag. 2020.

ALVES, R. S. Interações entre fatores e elementos do clima no percurso Ponte Nova - Viçosa - Ubá, Zona da Mata Mineira: identificação de diferentes ambientes termohigrométricos. 2015. 79 f. Monografia (Bacharel em Geografia) - Departamento de Geografia, Universidade Federal de Viçosa. Viçosa, 2015. Disponível em <http://www.geo.ufv.br/wp-content/uploads/2015/12/Rafael-deSouza-Alves.pdf>. Acesso em: 25 jul. 2020

CARLOS, A. F. A. (org). A geografia na sala de aula. São Paulo: Contexto, 2000. $144 p$.

COLLISCCHON, E. Variação temporal e espacial da precipitação: Uma experiência didática. In: SIMPOSIO BRASILEIRO DE CLIMATOLOGIA GEOGRÁFICA, 5, 2002, Curitiba. Anais..., Paraná: UFPR 2002. 
COLLISCHONN, E.; FIALHO, E. S. Problematizando a inscrição sociocultural do pensamento "politicamente correto" em tempos de mudanças climáticas. Boletim Gaúcho de Geografia. Porto Alegre, n. 33, p. 191-214, 2007. Disponível em: <https://seer.ufrgs.br/bgg/article/view/37435/24180>. Acesso em: 29 ago. 2012.

CORREA, W. S. C. Campo térmico e higrométrico da Regional Praia do Canto no município de Vitória (ES) 140f. Dissertação (Mestrado em Geografia) - Centro de Ciências Humanas e Naturais da UFES. Vitória, 2018. Disponível em: <https://repositorio.ufes.br/handle/10/3612>. Acesso em 18 ago. 2020.

COSTA, I. T.; WOLLMANN, C. A. A construção de instrumentos meteorológicos e o ensino dos elementos do clima em escolas do ensino básico do município de Itaara, RS. Ciência e Natura, Santa Maria-RS, v. 39, p. 189-206, 2017. Disponível em: <https://periodicos.ufsm.br/cienciaenatura/article/view/29339>. Acesso em: 19 ago. 2020.

DANNI-OLIVEIRA, I. M. Procedimento de aferição de termômetros para atividades de campo em climatologia geográfica. Raega - O Espaço Geográfico em Análise, Curitiba-PR, v. 6, n. 1, p. 75-80, 2002. Disponível em: <https://revistas.ufpr.br/raega/article/view/18517/12046>. Acesso em: 14 jun. 2020

DANTAS, S. P. O Ensino de Climatologia Geográfica: uma abordagem de intervenção sobre os conceitos básicos de Clima e Tempo. REGNE, Caicó-RN, v. 2, n. Especial, 2016. <http://www.periodicos.ufrn.br/revistadoregne>. Acesso em: 20 ago. 2020.

FIALHO, E. S.; VIEIRA, J. C. R.; MACHADO, D. V.; SILVA, A. P. R.; FREIRE, R. G. Enchentes, meio ambiente e planejamento: Um estudo de caso no município de Duque de Caxias. In: OLIVEIRA, R. S. (org.).: Baixada Fluminense: Novos estudos e desafios. Rio de Janeiro: Paradigma, 133-147p, 2004. Disponível em <https://www.researchgate.net/publication/308875369_Enchente_meio_ambie nte_e_planejamento_Estudo_de_caso_no_municipio_de_Duque_de_Caxias $>$. Acesso em: 19 mar. 2020.

FIALHO, E. S. Práticas do ensino de Climatologia através da observação sensível. Ágora, Santa Cruz do Sul-RS, v. 13, n. 1, p. 105-123, 2007. Disponível em: <https://online.unisc.br/seer/index.php/agora/article/view/112/71>. Acesso em: 20 ago. 2020.

FIALHO, E. S. A Geografia escolas e as questões ambientais. Revista Ponto de Vista. Viçosa-MG, n. 5, n. 1, p.49-63, 2008. Disponível em: <https://periodicos.ufv.br/RPV/article/view/9722>. Acesso em: 20 ago. 2020.

FIALHO, E. S. Ilha de calor em cidade de pequeno porte: Um caso de Viçosa, na Zona da Mata Mineira. São Paulo: FFLCH/USP, 2009. 259f. Tese (Doutorado em Geografia Física) - Faculdade de Filosofia, Letra e Ciências Humanas, Universidade de São Paulo. Disponível em: <https://www.teses.usp.br/teses/disponiveis/8/8135/tde-22022010-154045/ptbr.php>. Acesso em: 30 Ag. 2020.

FIALHO, E. S. Estudos climáticos em sítios urbanos e rurais. In: FIALHO, E.S.; SILVA, C. A. (Org.). Concepções e Ensaios da Climatologia Geográfica. Dourados-MS: UFGD, 2012, v. 1, p. 83-114. Disponível em: 
<https://www.researchgate.net/publication/327890815_ESTUDOS_CLIMATICOS _EM_SITIOS_URBANOS_E_RURAIS>. Acesso em: 26 ago. 2020.

FIALHO, E. S. As temáticas físicas e ambientais na Geografia Escolar. In: MAIA, D. (org.): Ensino de Geografia em debate. Salvador-BA: EDFBA, p. 91-113, 2014. $125 p$.

Disponível em:<https://www.researchgate.net/publication/323268120_As_tematicas_fisica s_e_ambientais_na_Geografia_Escolar>. Acesso em: 20 ago. 2020.

FIALHO, E. S. Climatologia: Ensino e emprego de Geotecnologias. Revista Brasileira de Climatologia, Curitiba-PR, v. 13, n. 1, p. 62-75, 2014. Disponível em: <https://revistas.ufpr.br/revistaabclima/article/view/33604>. Acesso em: 15 ago. 2020.

FIALHO, E. S. Compreendendo a relação entre fatores e elementos do clima, a partir do aproveitamento didático do campo térmico no município de ViçosaMG. Revista Ponto de Vista, Viçosa-MG, v. 8, n. 1, p. 62-75, 2019. Disponível em: <https://periodicos.ufv.br/RPV/article/view/9214>. Acesso em: 15 ago. 2020.

FIALHO, E. S. Por uma geografia climática escolar: o tempo e clima através das canções populares regionais. Revista Ponto de Vista, Viçosa-MG, v. 9, n. 1, p. 36-53, 2020. Disponível em: <https://periodicos.ufv.br/RPV/article/view/9628>. Acesso em: 26 ago. 2020.

INSTITUTO BRASILEIRO DE GEOGRAFIA E ESTATÍSTICA (IBGE). Disponível em: <http://www.ibge.gov.br>. Acessado em: agosto de 2020.

KATUTA, A. L. A leitura de mapas no ensino de Geografia. NUANCES: estudos sobre educação. Presidente Prudente-SP, v. 8, n. 8, p. 167-180, 2002. Disponível em: <https://revista.fct.unesp.br/index.php/Nuances/article/view/426>. Acesso em: 30 ago. 2020.

LEAL, L. S.; FERREIRA, F. C. L.; GOMES, L. M. O estudo dos fenômenos térmicos-ambientais através da metodologia em espiral. Scientia Plena, AracajúSE, v. 15, n. 7, 10p. 2019. Disponível em: <https://www.scientiaplena.org.br/sp/article/view/4829/2188>. Acesso em: 22 ago. 2020.

LIMA, M. G. Climatologia: Reflexões sobre o seu ensino no curso de Graduação em Geografia. In: SIMPÓSIO BRASILEIRO DE CLIMATOLOGIA GEOGRÁFICA, 7, 2006. Rondonópolis-MT, Anais..., Mato Grosso: UFMT, 2006, cd-rom.

MARCHI, O. A. M.; CALIJURI, M. L.; COSTA, S. H. G.; LUGÃO, W. G.; SOUZA, P. J. A.; Leitura e Caracterização da Paisagem em Auxílio ao Planejamento da Ocupação Urbana de Ponte Nova - MG. Natureza \& Desenvolvimento, ViçosaMG, v. 1, n. 1, p. 41-50, 2005. Disponível em <http://www.cbcn.org.br/arquivos/p_leitura_nova-mg_1379590217.pdf>. Acesso em: 30 ago. 2020.

MELO, H. L. S.; JOSÉ, R. V. S.; SANTOS, K. A.; GRECO, R. Dialogando com ensino de climatologia e a prática didática na Geografia. Revista de Geografia, Juiz de Fora-MG, v. 8, n. 2, p. 44-53, 2018. Disponível em: <https://periodicos.ufjf.br/index.php/geografia/article/view/25989/19000>. Acesso em: 27 ago. 2020. 
OLIVA, J.T; FONSECA, F. P. Reflexões sobre o urbano, a cartografia e a iconografia: o caso da metrópole de São Paulo. Revista Geografia e Pesquisa, Ourinhos-SP. v. 5, p. 11-38, 2011Disponível em: http://vampira.ourinhos.unesp.br/openjournalsystem/index.php/geografiaepesq uisa/article/view/140. >. Acesso em: 15 ago. 2020.

OLIVEIRA, W. D. O campo térmico do distrito de Carapina-Serra-ES: Estude de caso em áreas litorâneas. 200f. Dissertação (Mestrado em Geografia) - Centro de Ciências Humanas e Naturais da UFES. Vitória, 2018. Disponível em: <http://www.geografia.ufes.br/pt-br/pos-graduacao/PPGG/detalhes-datese?id=12880 $>$. Acesso em 17 ago. 2020.

PRADO, L. B.; ALVES, L. A.; FIALHO, E. S. A variação da temperatura do ar, ao longo do percurso Ponte Nova-Ubá (Brasil) no anos de 2014 e 2015. Cadernos de Geografia, Coimbra-PORT, n. 37, v. 1, p. 55-69, 2018. Disponível em: <https://impactum-journals.uc.pt/cadernosgeografia/article/view/37_5>. Acesso em: 31 ago. 2020.

ROCHA, V. M.; FIALHO, E. S. Uso da terra e suas implicações na variação termohigrométrica ao longo de um transeto campo-cidade no município de Viçosa-MG. Revista de Ciências Humanas, Viçosa-MG, v. 10. n. 1, p. 64-77, 2010. Disponível em: <https://periodicos.ufv.br/RCH/article/view/3494>. Acesso em: 5 ago. 2020.

ROSSATO, M. S.; SILVA, D.L.M. Da cotidianidade do tempo meteorológico à compreensão de conceitos climatológicos. In: REGO, N.; CATROGIOVANNI, A. C; KAERCHER, N. A (Orgs.). Geografia: praticas pedagógicas para o Ensino Médio. Porto Alegre: Artmed, 2007.p.10 3-110

SENNETT, R. A corrosão do caráter: Conseqüências pessoais no novo capitalismo. 7. ed. Traduzido por Marcos Santarrita. Rio de Janeiro: Record, 2003. 204p.

SILVA, M. S.; CARDOSO, C. Desafios e perspectivas para o ensino de Climatologia Geográfica na escola. Geosaberes, Fortaleza-CE, v. 10, n. 20, p. 117, $2019 . \quad$ Disponível em: <http://www.geosaberes.ufc.br/geosaberes/article/view/691>. Acesso em: 21 ago. 2020.

SIMIELLI, M. E. R. Cartografia no ensino fundamental e médio. In: CARLOS, A. F. A. A Geografia na sala de aula. São Paulo-SP: Contexto, 1999. p. 92-108.

SMITH, F. Lendo, escreveFndo e pensando. In: SMITH. F. (org.).: Compreendendo a Leitura: Uma análise psicolinguística da leitura e do aprender a ler. Porto Alegre-RS: Artes Medicas, 1989. p.198-215.

STEINKE, E. T. Prática pedagógica em climatologia no ensino fundamental: Sensações e representações do cotidiano. Acta Geográfica, Boa Vista-RR, Ed. Esp. Climatologia Geográfica, p.77-86, 2012. Disponível em: <https://revista.ufrr.br/actageo/article/view/1095>. Acesso em: 20 ago. 2020.

STEINKE, E. T.; STEINKE, V. A; VASCONCELOS, V. C. Produção científica a respeito do Ensino de Climatologia nos simpósios brasileiros de climatologia geográfica. Revista Brasileira de Climatologia, Curitiba-PR, Ano 10, v. 14, p. 132-153, 2014, Disponível: <https://revistas.ufpr.br/revistaabclima/article/view/38174>. Acesso em: 21 ago. 2020. 